\title{
Sustainability and digitalization in supply chains: A bibliometric analysis
}

\author{
Andrés Muñoz-Villamizar ${ }^{a, c^{*}}$, Elyn Solano ${ }^{a}$, Carlos Quintero-Araujo ${ }^{a}$ and Javier Santos $^{b}$
}

\begin{abstract}
${ }^{a}$ Operations and Supply Chain Management Research Group, Escuela Internacional de Ciencias Económicas y Administrativas, Universidad de La Sabana, Chía, Colombia

${ }^{b}$ Universidad de Navarra, TECNUN Escuela de Ingenieros, San Sebastián, Spain

${ }^{c}$ Center for Transportation \& Logistics, Massachusetts Institute of Technology, Cambridge, MA, USA

C H R O N I C L E

Article history:

Received February 1, 2019

Received in revised format March

1, 2019

Accepted March 212019

Available online

March 222019

Keywords:

Sustainability

Digitalization

Supply chain

Bibliometric analysis

Scopus

VOSviewer
\end{abstract}

\section{Introduction}

Supply chains can be defined as "the network of organizations that are involved, through upstream and downstream linkages, in the different processes and activities that produce value in the form of products and services in the hands of the ultimate consumer" (Mangan \& Lalwanii, 2016, p.10). In the present global environment, these organizational structures operate in complex and dynamic markets (Yang et al., 2011) mainly affected by technological developments (Büyüközkan \& Göçer, 2018). The accelerated pace in digitalization of processes has transformed the business dynamic and market structure (Kayikci, 2018; Waluyo, 2019), affecting supply chain management (Ward et al., 2017; Büyüközkan \& Göçer, 2018; Naway et al., 2019). The confluence of internet, wireless, predictive

* Corresponding author

E-mail address: andres.munoz1@unisabana.edu.co (A. Muñoz-Villamizar)

C 2019 by the authors; licensee Growing Science.

doi: $10.5267 /$ j.uscm.2019.3.002 
analytics and cloud technologies (i.e., digitalization) have changed the entire supply chain operations and has brought more value out of it (Yang et al., 2011).

At the same time, supply chain management is confronted by the constant growth of capital and consumer goods in the global demand by persistently verifying overall interests for social, environmental and economic aspects (Manavalan \& Jayakrishna, 2019; Sabara et al., 2019). Therefore, in addition to technological and digital parameters, social and environmental dimensions are considered as important for supply chain performance (Dossou, 2018). As an example, digitalization has the immense opportunity to reduce emissions from logistics as much as 10 to $12 \%$ by 2025 and to help decarbonize the global economy (World Economic Forum, 2016). Consequently, the aim with the digitalization of supply chains should be considered to a transformative change towards 'sustainability' (Kayikci, 2018).

The term 'sustainability' can be defined as expanding the corporate perspective to one that considers environmental, social and economic aspects (i.e., triple bottom line) (Abdul-Rashid et al., 2017). This concept, first introduced in 1987 (Brundtland, 1987), has been witnessed in the subsequent emergence and adoption of environmental practices and standards, either in relation to production (life cycle analysis, green building standards, etc.) or to management procedures (environmental management system) in business and supply chains (Muñoz-Villamizar et al., 2018). Hence, beginning from the 1990s, new terms, such as reverse logistics, green logistics, and green supply chain, have appeared (Hou et al., 2015). Therefore, the increasing focus on sustainable practices and information and communications technology tools has led academia and industry to address sustainable and digital supply chains in different ways (Papetti et al., 2019). For example, Sabat (2002) described how emerging mobile wireless were unleashing the potential of the value chain in early 2002. Nunes et al. (2006) discussed the opportunities for a supply chain optimization in the automotive industry using Radio Frequency Identification (RFID) technology. Shrouf et al. (2014) discussed the role of the Internet of Things in sustainable supply chains with the objective of achieving energy efficiency. Hazen et al. (2016) studied the nature of big data analytics impact on supply chain sustainability. Kayikci (2018) highlighted the benefits of the digitalization of logistics process and examined the sustainability impact of digitalization in logistics. More recently, Manavalan and Jayakrishna (2019) presented a literature review of Internet of Things, sustainable supply chains and Industry 4.0. Based on this investigation, the authors prosed a framework for assessing the preparedness of supply chains for a sustainable growth to meet industry 4.0.

Although the abovementioned literature review, as well as other works, provides valuable information on the state of the literature on sustainable and digital supply chains, there is still much need for a bibliometric approach for analyzing this literature (Amirbagheri et al., 2018). Bibliometric studies are becoming very popular in the scientific literature, strongly motivated by access to bibliographic information (Merigó et al., 2018). To the best of our knowledge, there are no studies that have analyzed sustainable and digital supply chains research from a bibliometric analysis perspective. In that sense, this paper aims to fulfill this gap in the literature.

The major contributions of the paper are highlighted as follows: 1) A detailed bibliometric analysis of sustainability and digitalization in supply chains has been conducted using the most widely used database (i.e., Scopus); 2) the research growth of sustainability and digitalization in supply chains is documented from 2002 to 2018 ; 3) the most common parameters (e.g., highly productive authors, most influential authors, most cited discipline, countries, and highly prolific institutions, etc.) are discussed; 4) the conceptualization of this topic over the years is presented using the most common keywords used in the field; and 5) the main two research clusters for this topic are defined.

The rest of this paper is organized as follows. Section 2 describes the proposed research method. Section 3 presents the analysis of the papers we identified from our bibliometric approach. Finally, 
section 4 concludes the paper by presenting some concluding remarks in addition to guidelines for future research.

\section{Methodology}

Bibliometrics is usually defined as a collection of research techniques that studies quantitatively the bibliographic material (Pritchard 1969; Merigó et al., 2018; Pourkhani et al., 2019). These bibliometric analyses are based on quantitative and reliable data (i.e., indexed publications). Therefore, the bibliometric analysis is based on a stable foundation of knowledge and not (for example) on the hardly verifiable opinions of expert groups (Zemigala, 2019). This method has been used in management research to improve the understanding of theoretical structures in logistics and supply chain management but also in various other fields (e.g., management information systems, operations management, international management, etc.) (Bensalem \& Kin, 2019).

From an academic point of view, it is important that the published material in a specific research field, such as sustainability and digitalization in supply chains, could be classified so that researches and practitioners can follow all the field's advances and trends (Gaviria-Marin et al., 2019). In recent years, technological advances have also facilitated the development of bibliometric analysis, which has become an increasingly popular technique among researchers (Ding et al., 2014).

The summary of the methodology for conducting the search is shown in Table 1. Our bibliometric analysis is based on literature recorded in the Scopus citation database (www.scopus.com). The decision to choose this database is based on the fact that "Scopus is the largest abstract and citation database of peer-reviewed literature: scientific journals, books and conference proceedings." (Elsevier, 2019). Scopus indexes many serial and non-serial publications and millions of conference papers, including the majority of the most important journals in the field of operations management research as listed in Barman et al. (2001), Olson (2005) and Theoharakis et al. (2007).

\section{Table 1}

Summary of used methodology

\begin{tabular}{|c|c|}
\hline Unit of analysis & $\begin{array}{l}\text { Relevant books and articles whose main content focuses on the links between supply chains, } \\
\text { sustainability and digitalization }\end{array}$ \\
\hline Type of analysis & Qualitative and quantitative \\
\hline Period of analysis & $2002-2018$ \\
\hline Search engines & Scopus \\
\hline Query string & $\begin{array}{l}\text { Using the keywords that were associated with each of the concepts of this research, the } \\
\text { following query string was created: } \\
\text { TITLE-ABS-KEY ( ( "supply chain" OR "supply chains" OR scm OR "supply chain } \\
\text { management" ) AND ( sustainable OR sustainability) AND ( digitalization OR smart OR } \\
\text { digital OR digitalisation OR digitization OR "Communication Technologies" OR "industry } \\
\text { 4.0" ) ) AND (EXCLUDE ( PUBYEAR, 2020) OR EXCLUDE (PUBYEAR, 2019)) }\end{array}$ \\
\hline $\begin{array}{l}\text { Tota } \\
\text { eval }\end{array}$ & \\
\hline
\end{tabular}

In the first stage, the keywords 'supply chain' and 'digitalization' and 'sustainability' were entered in the search tool of Scopus to obtain a first list of works combining these three terms in the title, abstract or keywords. Using keywords of these early results, a new and complete search equation (i.e., query string) was defined (see Table 1). The results were then filtered by subject area, keywords and year using tools within Scopus. Text mining software called VOSviewer, developed by van Eck and Waltman (2010) was also applied to detect nonrelevant repeating terms and exclude them from the list. A continuous combination of text mining and Scopus filtering tools narrowed down the number of hits until text mining no longer showed any irrelevant clusters of terms. 
This generic search identified 484 publications published between 2002 and 2018. Although, the year 1987 can be defined as the starting point for the concept sustainability (Brundtland, 1987), it is important to note that digitalization was enabled by the diffusion of Internet-based information and communication technologies at the beginning of the years 2000 (Bicocchi et al., 2019). Consequently, first publication on sustainability and digitalization in the supply chain is dated on 2002. Finally, results from 2019 (and 2020) are excluded in the chart to avoid showing partial statistics (see Table 1). It is to note that in the remainder of this article, the documents identified by Scopus are generally referred to as papers and articles, even though some of them are book chapters.

\section{Results}

According to Noyons et al. (1999), bibliometrics combines two main procedures: performance analysis and science mapping. Within performance analysis, there is descriptive bibliometrics (that is used for trend analysis in scientific research based primarily on research centers, journals or regions); and evaluative bibliometrics that is used to assess academic centers or researchers, based primarily on citation indexes of articles (Zemigala, 2019). The study of these statistics allows one to grasp the trends of the research field including the most influential authors and the most cited references (Bensalem \& Kin, 2019). On the other hand, science mapping is a spatial representation of how different scientific actors are related to one another (Small, 1999). In this sense, this bibliometric component shows the structural and dynamic aspects of scientific research using, for example: the co-occurrence of keywords in documents, the co-citation analysis using pairs of documents that are commonly cited together, the most important journals, etc. (Gaviria-Marin et al., 2019). This section presents both analysis with their corresponding elements.

\subsection{Annual citation and scientific disciplines}

As mentioned before, the very first paper on sustainability and digitalization in supply chain management was published in 1992. Since then, the number of published papers on this topic has grown, especially in 2017. To better understand this trend, Table 2 reports the number of published papers and their total citations. Additionally, Table 2 identifies the range of highly cited papers relative to those with one or five citations.

Table 2

Annual citation

\begin{tabular}{|c|c|c|c|c|c|c|c|c|}
\hline Years & TP & $\geq 100$ & $\geq 50$ & $\geq 20$ & $\geq 10$ & $\geq 5$ & $\geq 1$ & TC \\
\hline 2002 & 1 & 0 & 0 & 0 & 0 & 0 & 1 & 1 \\
\hline 2003 & 3 & 0 & 0 & 0 & 0 & 1 & 1 & 6 \\
\hline 2004 & 9 & 0 & 0 & 0 & 3 & 3 & 3 & 50 \\
\hline 2005 & 8 & 0 & 0 & 0 & 1 & 3 & 5 & 30 \\
\hline 2006 & 3 & 1 & 1 & 1 & 1 & 1 & 2 & 869 \\
\hline 2007 & 10 & 1 & 2 & 3 & 3 & 3 & 6 & 205 \\
\hline 2008 & 10 & 0 & 0 & 1 & 3 & 4 & 6 & 73 \\
\hline 2009 & 2 & 1 & 1 & 1 & 1 & 1 & 2 & 153 \\
\hline 2010 & 16 & 0 & 0 & 0 & 1 & 3 & 12 & 43 \\
\hline 2011 & 18 & 0 & 1 & 1 & 2 & 4 & 6 & 79 \\
\hline 2012 & 20 & 1 & 1 & 3 & 4 & 6 & 11 & 293 \\
\hline 2013 & 27 & 1 & 2 & 2 & 3 & 9 & 16 & 219 \\
\hline 2014 & 32 & 2 & 3 & 5 & 7 & 8 & 17 & 446 \\
\hline 2015 & 35 & 0 & 0 & 4 & 5 & 10 & 23 & 152 \\
\hline 2016 & 38 & 0 & 2 & 5 & 9 & 14 & 26 & 306 \\
\hline 2017 & 159 & 0 & 0 & 7 & 12 & 21 & 60 & 404 \\
\hline 2018 & 93 & 0 & 0 & 3 & 5 & 12 & 44 & 238 \\
\hline Total & 484 & 7 & 13 & 36 & 60 & 103 & 241 & 3567 \\
\hline$\%$ & $100 \%$ & $1 \%$ & $3 \%$ & $7 \%$ & $12 \%$ & $21 \%$ & $50 \%$ & \\
\hline
\end{tabular}

During the first 8 years of the time period studied in this paper, the number of published papers on sustainability and digitalization in supply chains had not exceeded 10. After this period, there had been a slight growth in the number of published papers on this topic, with a maximum of 38 papers in 2016. 
However, in 2017, the number of published papers had a huge increase compared to previous years. The amount of published research articles in 2017 was 159 (i.e., 33\% of total sample). Regarding citations, it should be noted that only $1 \%$ of the papers have received more than one hundred citations, that are 7 out of 484 papers. In addition, $3 \%$ of the papers have received more than 50 citations and $7 \%, 12 \%, 21 \%$ and $50 \%$ of the papers have received more than twenty, ten, five and one citations, respectively. It is also important to highlight that recently published articles (those published in the last 5 years) represent about $43 \%$ of total cites (1546 out of 3567 citations).

The next step is to analyze the most important scientific disciplines. In order to define areas of science are focused on research on sustainability and digitalization in the supply chain, the taxonomy of scientific areas considered by Scopus database was used. In the general set, articles have been assigned to 14 different disciplines (see Table 3). Engineering clearly occupied the first place due to the nature of the considered topics (i.e. sustainability, digitalization and supply chains). The scientific disciplines from positions 1-4 were considered as leading and the rates in each of these areas were similar dozen percent of the total general dataset. It is important to highlight that Energy discipline represents $15 \%$ of the total sample. A thorough analysis of the results in section 3.3 allows a surmise that future research in the Energy field is going to be a leading one. The disciplines from items 5-7 obtained interest rates in the general set of half dozen or so percent. Positions 8-13 represent the less important disciplines. The differences between these disciplines were not significant, as they reached similar percent. Finally, unimportant disciplines as Physics and Astronomy, Biochemistry, Genetics and Molecular Biology, Chemistry, etc., are groped in other categories, as they only represent $2.9 \%$ of total share.

Table 3

Research on sustainability and digitalization in the supply chain according to scientific disciplines

\begin{tabular}{llcc}
\hline Rank & Subject area & Papers & \% \\
\hline \multirow{3}{*}{$\begin{array}{l}\text { 1. Leading, large, several dozen } \\
\text { percent share }\end{array}$} & Engineering & 239 & $25.3 \%$ \\
& Energy & 142 & $15.0 \%$ \\
& Computer Science & 134 & $14.2 \%$ \\
& Business, Management and Accounting & 110 & $11.6 \%$ \\
\hline \multirow{2}{*}{$\begin{array}{l}\text { 2. Significant, medium, several } \\
\text { percent share }\end{array}$} & Environmental Science & 71 & $7.5 \%$ \\
& Decision Sciences & 60 & $6.3 \%$ \\
& Social Sciences & 52 & $5.5 \%$ \\
\hline \multirow{3}{*}{ 3. Less important, small, at most } & Agricultural and Biological Sciences & 24 & $2.5 \%$ \\
a few percent share & Materials Science & 22 & $2.3 \%$ \\
& Economics, Econometrics and Finance & 20 & $2.1 \%$ \\
& Chemical Engineering & 19 & $2.0 \%$ \\
\hline 4. Unimportant, minimal, at most & Others & 15 & $1.6 \%$ \\
\hline
\end{tabular}

\subsection{Leading journals, authors, institutions and countries}

Table 4 shows the top 14 journals. The journal with the largest number of articles is "IFIP Advances in Information and Communication Technology" ( $\mathrm{TP}=20$ documents). However, the most important journal that was focused on sustainability and digitalization in the supply chains was the "Journal of Cleaner Production", as it has the highest number of citations from the general dataset appeared there $(\mathrm{TC}=446)$ and the highest average citation per document $(\mathrm{C} / \mathrm{D}=26.2)$. In addition, this title had the highest impact factor SJR (Scimago Journal \& Country Rank, 2019) among the reported sources. Other journals with important average citations per document are "Supply Chain Management" and "International Journal of Production Research". Although "IFIP Advances in Information and Communication Technology" and "Sustainability Switzerland" have more than 10 documents, their SJR factor and average citation per document are quite low. 
Table 4

Sources with the highest number of articles

\begin{tabular}{|c|c|c|c|c|}
\hline Source & SJR & TP & TC & C/D \\
\hline IFIP Advances in Information and Communication Technology & 0.18 & 20 & 14 & 0.7 \\
\hline Journal Of Cleaner Production & 1.47 & 17 & 446 & 26.2 \\
\hline Sustainability Switzerland & 0.54 & 13 & 42 & 3.2 \\
\hline IOP Conference Series Materials Science and Engineering & 0.2 & 9 & 0 & 0.0 \\
\hline Advanced Materials Research & 0.12 & 6 & 2 & 0.3 \\
\hline ACM International Conference Proceeding Series & 0.16 & 5 & 6 & 1.2 \\
\hline International Journal of Production Research & 1.43 & 5 & 53 & 10.6 \\
\hline Procedia CIRP & 0.67 & 5 & 27 & 5.4 \\
\hline Applied Mechanics and Materials & 0.12 & 4 & 0 & 0.0 \\
\hline Ceur Workshop Proceedings & 0.17 & 4 & 0 & 0.0 \\
\hline Lecture Notes in Computer Science & 0.29 & 4 & 2 & 0.5 \\
\hline Procedia Manufacturing & 0.2 & 4 & 11 & 2.8 \\
\hline Smart Innovation Systems and Technologies & 0.17 & 4 & 2 & 0.5 \\
\hline Supply Chain Management & 1.99 & 4 & 97 & 24.3 \\
\hline
\end{tabular}

Explanation. $\mathrm{SJR}=$ Scimago Journal Rank in 2017; $\mathrm{TP}=$ Total papers; $\mathrm{TC}=$ Total citations; $\mathrm{C} / \mathrm{D}=$ average citation per document.

As pointed out by Amirbagheri et al. (2018) and Jelvehgaran Esfahani et al. (2019), a valuable point of view is obtained by data on authors, universities and countries of papers citing the topic under study. This analysis provides essential information about sustainability and digitalization in the supply chain literature. Table 5 shows the top 10 authors, universities and countries by the number of documents; while Table 6 shows the top 10 by total citations (TC).

Table 5

Top 10 number of documents: authors, institutions and countries

\begin{tabular}{|c|c|c|c|c|c|c|c|c|c|}
\hline $\mathbf{R}$ & Author & TP & TC & Institution & TP & TC & Country & $\mathbf{T P}$ & TC \\
\hline 1 & Lv, X. & 4 & 0 & Xi'an Jiaotong University & 7 & 2 & United States & 84 & 1782 \\
\hline 2 & Sayogo, D.S. & 4 & 16 & Shanghai Jiao Tong University & 6 & 13 & United Kingdom & 62 & 325 \\
\hline 3 & Weng, Y. & 4 & 0 & Ministry of Education China & 5 & 0 & China & 54 & 72 \\
\hline 4 & Zhang, J. & 4 & 16 & Delft University of Technology & 5 & 112 & Italy & 32 & 251 \\
\hline 5 & Andersen, D.F. & 3 & 14 & Cardiff University & 5 & 12 & Netherlands & 21 & 451 \\
\hline 6 & Bechtsis, D. & 3 & 29 & Huazhong University of Science and Technology & 5 & 1 & Germany & 20 & 88 \\
\hline 7 & Bo, $\mathrm{Z}$. & 3 & 0 & University of Cambridge & 5 & 50 & India & 17 & 114 \\
\hline 8 & Goudarzi, N. & 3 & 3 & University of Manchester & 4 & 45 & Australia & 16 & 64 \\
\hline 9 & Kumaraswamy, M.M. & 3 & 26 & Zhejiang University & 4 & 0 & Canada & 12 & 197 \\
\hline 10 & La Scalia, G. & 3 & 24 & Dalian University of Technology & 4 & 10 & Spain & 12 & 34 \\
\hline
\end{tabular}

Explanation. $\mathrm{TP}=$ Total papers; $\mathrm{TC}=$ Total citations

Table 6

Top 10 citations: authors, institutions and countries

\begin{tabular}{clllllllll}
\hline R & Author & TP & TC & Institution & TP & TC & Country & TP & TC \\
\hline 1 & Sarkis j. & 3 & 129 & University of Alabama & 1 & 868 & United States & 84 & 1782 \\
2 & Bechtsis D. & 3 & 29 & Georgia State university & 1 & 868 & Netherlands & 21 & 451 \\
3 & Tsolakis N. & 3 & 29 & UCLA & 2 & 197 & United Kingdom & 62 & 325 \\
4 & Kumaraswamy M.M. & 3 & 26 & Sustainable operations solutions & 1 & 196 & Italy & 32 & 251 \\
5 & La Scalia G. & 3 & 24 & University of Massachusetts & 1 & 196 & Canada & 12 & 197 \\
6 & Micale R. & 3 & 24 & Rockwell automation & 1 & 196 & Switzerland & 7 & 170 \\
7 & Sayogo D.S. & 4 & 16 & University of Texas & 1 & 196 & India & 17 & 114 \\
8 & Zhang J. & 4 & 16 & University of Groningen & 1 & 168 & Germany & 20 & 88 \\
9 & Andersen D.F. & 3 & 14 & Elon university & 1 & 151 & Portugal & 8 & 85 \\
10 & Luna-Reyes L.F. & 3 & 14 & Ouroboros holdings, llc. & 1 & 151 & Finland & 6 & 83 \\
\hline
\end{tabular}

Explanation. $\mathrm{TP}=$ Total papers; $\mathrm{TC}=$ Total citations

Upon further examination of the number of citations, the distribution changes. That is, considering authors, institutions and countries with the largest number of documents do not necessarily have the highest number of citations. For example, the largest number of articles on sustainability and digitalization in the supply chain was published by the Xi'an Jiaotong University. Unfortunately, 
despite being the leading publisher of articles in the quantitative aspect (number of articles), this center has been poorly cited (i.e., it only has 2 citations). In contrast, University of Alabama has only 1 document but 868 citations. However, it is important to note that the United States appear in first place in both tables (configurations). This result is in accordance with the Bibliographic coupling of countries using VOSviewer software (see Fig. 1).

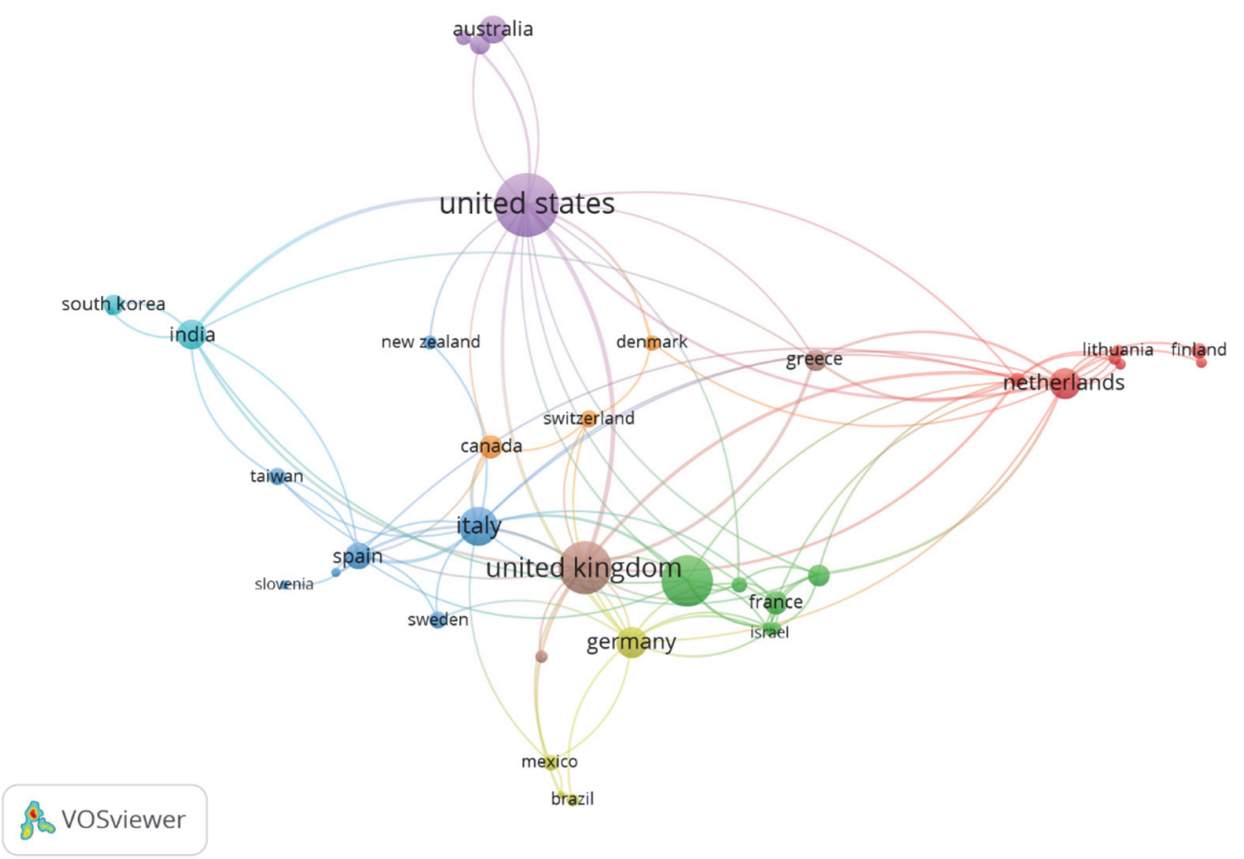

Fig. 1. Bibliographic coupling of countries

\subsection{Keywords mapping}

Finally, we used the analysis of keywords provided by the authors' publications. The previous part has focused the analysis on general results concerning leading authors, institutions and countries in the field of sustainability and digitalization in the supply chain. However, it is also useful to examine such outputs as co-occurrence of keywords.

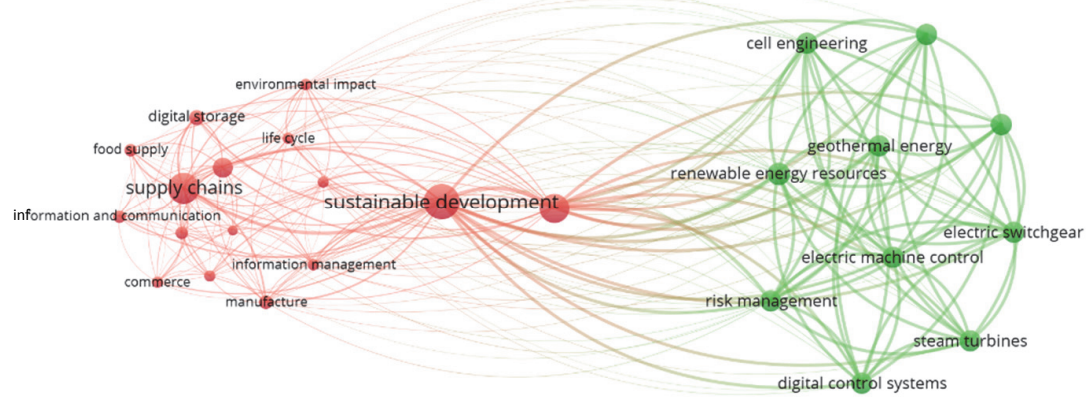

\& vosviewer

Fig. 2. Co-occurrence of author keywords of evaluated documents 


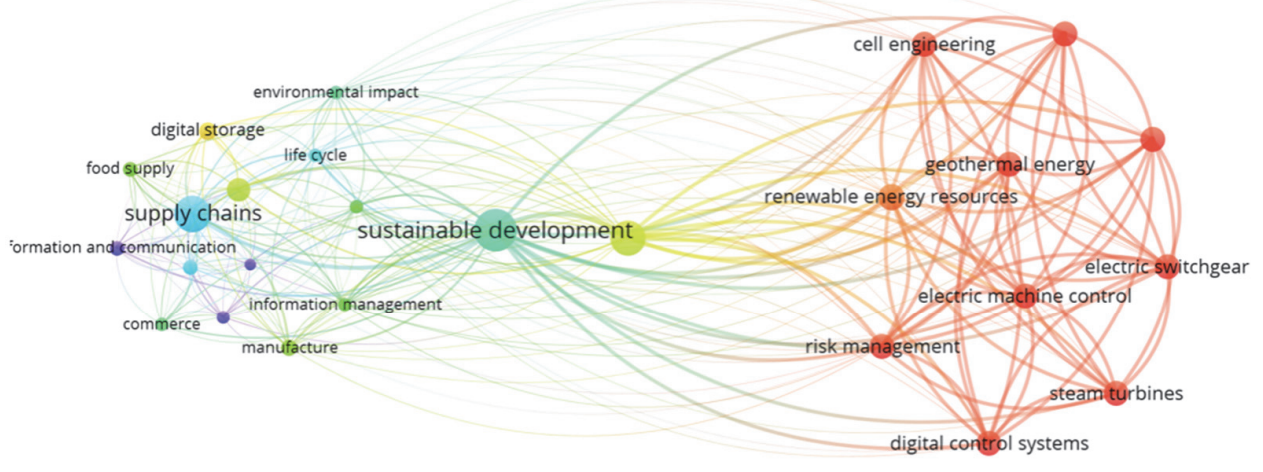

is VOSviewer

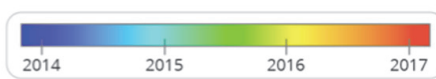

Fig. 3. Timeline visualization of co-occurrence of author keywords of evaluated documents

To this end, this study uses VOSviewer software (Van Eck and Waltman 2010). In the special set, 4049 different keywords were identified. Fig. 2 shows the 26 most frequent keywords that have been repeated at least 20 times. As it can be seen, the two different clusters are separated by distinct colors (i.e., red and green). Therefore, it can be stated that the topic under the study is structured around 2 clusters (1) Supply chain management and sustainability, concepts and practices (e.g., life cycle analysis, manufacturing, environmental impact, etc.) and (2) energy related technologies (e.g., renewable energy sources, steam turbines, cell engineering, etc.). Moreover, and to gain a deeper insight into the results presented in Fig. 2, Fig. 3 shows the timeline visualization of co-occurrence of author keywords of evaluated documents. That is an evolution of keywords usage along the years (2002-2018). Regarding this evolution, it can be stated that first approaches about sustainability and digitalization in the supply chain correspond to 'formation and communication', 'competition' and 'innovation'. Nowadays, keywords have evolved to the energy related technologies (i.e. green cluster).

\section{Conclusions and future research}

This article presents a bibliometric analysis with the aim of investigating the contributions and interrelations between sustainability and digitalization in the supply chain management. This analysis is based on a sample with 484 papers. The dynamics of research on this topic, in chronological terms, are growing. It must be stressed that it has been an important number of publications in the 2017 . The leading scientific areas are Engineering, Energy, Computer Science and Business, Management and Accounting. Engineering proved to be an essential area of study. "The Journal of Cleaner Production" should be considered as the most focused journal on these topics. The most important institution contributing to the field by the number of documents is Xi'an Jiaotong University. In terms of total citations, the leading institution is University of Alabama. In geographical terms, the most prolific region is United States (by number of documents and by total citations). Finally, our research identified contributions and gaps in this body of knowledge; where the USA is the most influential country; and the topic is structured around 2 clusters (1) Supply chain management, concepts and practices and (2) energy related technologies. It is worth to emphasize the originality of the research carried out. To the best of our knowledge, there are no bibliometric analyses focusing strictly on scientific research on sustainability and digitalization in supply chains. Moreover, for the first time, we have presented a broad spectrum of trends or concentrations in terms of dynamics in time, scientific areas, research centers, journals, countries or thematic areas. Our results may facilitate the planning, designing, running and publishing of future research on this topic 


\section{References}

Abdul-Rashid, S., Sakundarini, N., Raja Ghazilla, R., \& Thurasamy, R. (2017). The impact of sustainable manufacturing practices on sustainability performance. International Journal of Operations \& Production Management, 37(2), 182-204.

Amirbagheri, K., Núñez-Carballosa, A., Guitart-Tarrés, L., \& Merigó, J. (2018). Research on green supply chain: a bibliometric analysis. Clean Technologies and Environmental Policy, 21(1), 3-22.

Barman, S., M. D. Hanna, and R. L. LaForge. (2001). Perceived relevance and quality of POM journals: A decade later. Journal of Operations Management, 19(3), 367-385.

Bensalem, A. and Kin, V. (2019). A bibliometric analysis of reverse logistics from 1992 to 2017. Supply Chain Forum: An International Journal, 20(1), 15-28.

Bicocchi, N., Cabri, G., Mandreoli, F., Mecella, M. (2019). Dynamic digital factories for agile supply chains: An architectural approach. Journal of Industrial Information Integration. doi: 10.1016/j.jii.2019.02.001. In press.

Brundtland, G., 1987. Our Common Future: Report of the 1987 World Commission on Environment and Development. Oxford University Press, Oxford.

Büyüközkan, G. and Göçer, F. (2018). Digital supply chain: Literature review and a proposed framework for future research. Computers in Industry, 97, 157-177.

Dossou, P. (2018). Impact of Sustainability on the supply chain 4.0 performance. Procedia Manufacturing, 17, 452-459. doi: 10.1016/j.promfg.2018.10.069

Elsevier (2019). Available online at: https://www.elsevier.com/solutions/scopus (last access, 8 March 2019).

Gaviria-Marin, M., Merigó, J., \& Baier-Fuentes, H. (2019). Knowledge management: A global examination based on bibliometric analysis. Technological Forecasting and Social Change, 140, 194-220.

Hazen, B., Skipper, J., Ezell, J., \& Boone, C. (2016). Big data and predictive analytics for supply chain sustainability: A theory-driven research agenda. Computers \& Industrial Engineering, 101, 592598.

Hou, H., Chaudhry, S., Chen, Y., \& Hu, M. (2015). Physical distribution, logistics, supply chain management, and the material flow theory: a historical perspective. Information Technology and Management, 18(2), 107-117.

Esfahani, H., Tavasoli, K., \& Jabbarzadeh, A. (2019). Big data and social media: A scientometrics analysis. International Journal of Data and Network Science, 3(3), 145-164.

Kayikci, Y. (2018). Sustainability impact of digitization in logistics. Procedia Manufacturing, 21, $782-$ 789.

Manavalan, E., \& Jayakrishna, K. (2019). A review of Internet of Things (IoT) embedded sustainable supply chain for industry 4.0 requirements. Computers \& Industrial Engineering, 127, 925-953.

Mangan, J., \& Lalwanii, CH (2016). Global logistics and supply chain management. 3rd ed. John Wiley $\&$ Sons, New York, USA.

Merigó, J., Muller, C., Modak, N., Laengle, S. (2018). Research in production and operations management: A university-based bibliometric analysis. Global Journal of Flexible Systems Management, 20(1), 1-29.

Muñoz-Villamizar, A., Santos, J., Viles, E., \& Ormazábal, M. (2018). Manufacturing and environmental practices in the Spanish context. Journal of Cleaner Production, 178, 268-275.

Naway, F., \& Rahmat, A. (2019). The mediating role of technology and logistic integration in the relationship between supply chain capability and supply chain operational performance. Uncertain Supply Chain Management, 7(3), 553-566.

Noyons, E. C., Moed, H. F., \& Luwel, M. (1999). Combining mapping and citation analysis for evaluative bibliometric purposes: A bibliometric study. Journal of the American society for Information Science, 50(2), 115-131.

Nunes, K., Schnatmeyer, M., Thoben, K., \& Valle, R. (2006). Using RFID for waste minimization in the automotive industry. IFAC Proceedings Volumes, 39(3), 221-226. 
Olson, J. E. (2005).Top-25-Business-school professors rate journals in operations management and related fields. Interfaces, 35(4), 323-338.

Papetti, A., Marconi, M., Rossi, M., \& Germani, M. (2019). Web-based platform for eco-sustainable supply chain management. Sustainable Production and Consumption, 17, 215-228.

Pourkhani, A., Abdipour, K., Baher, B., \& Moslehpour, M. (2019). The impact of social media in business growth and performance: A scientometrics analysis. International Journal of Data and Network Science, 3(3), 223-244.

Pritchard, A. (1969). Statistical bibliography or bibliometrics. Journal of Documentation, 25(4), 348349.

Sabara, Z., Soemarno, S., Leksono, A., \& Tamsil, A. (2019). The effects of an integrative supply chain strategy on customer service and firm performance: an analysis of direct versus indirect relationships. Uncertain Supply Chain Management, 7(3), 517-528.

Sabat, H. (2002). The evolving mobile wireless value chain and market structure. Telecommunications Policy, 26(9-10), 505-535.

Shrouf, F., Ordieres, J., \& Miragliotta, G. (2014). Smart factories in Industry 4.0: A review of the concept and of energy management approached in production based on the Internet of Things paradigm. 2014 IEEE International Conference On Industrial Engineering And Engineering Management. doi: 10.1109/ieem.2014.7058728.

Scimago Journal \& Country Rank (2019). Journal Rankings. Available online at: https://www.scimagojr.com/ (last access 11 March 2019).

Small, H. (1999). Visualizing science by citation mapping. Journal of the American society for Information Science, 50(9), 799-813.

Theoharakis, V., Voss, C., Hadjinicola, G. C., \& Soteriou, A. C. (2007). Insights into factors affecting Production and Operations Management (POM) journal evaluation. Journal of Operations Management, 25(4), 932-955.

van Eck, N., \& Waltman, L. (2009). Software survey: VOSviewer, a computer program for bibliometric mapping. Scientometrics, 84(2), 523-538.

Waluyo, W. (2019). Does computerized accounting system increase the supply chain accuracy? An empirical evidence from Indonesian supply chain companies. Uncertain Supply Chain Management, 7(3), 541-552.

Ward, M., Halliday, S., Uflewska, O., Wong, T. (2017). Three dimensions of maturity required to achieve future state, technology-enabled manufacturing supply chains. Proceedings of The Institution of Mechanical Engineers, Part B: Journal Of Engineering Manufacture, 232(4), 605620.

WCED (1987). Our Common Future. World Commission on Environment and Development. Oxford University Press, Oxford, UK.

World Economic Forum (2016). Digital Transformation of Industries: Logistics Industry. Available online at: http://reports.weforum.org/digital-transformation (last access, 11 March 2019).

Yang, F., Wu. D., Liang, L. Bi, G., Wu, D.D. (2011). Supply chain DEA: Production possibility set and performance evaluation model. Annals of Operations Research, 185(1), 195-211

Zemigala, M. (2019). Tendencies in research on sustainable development in management sciences. Journal of Cleaner Production, 218, 796-809.

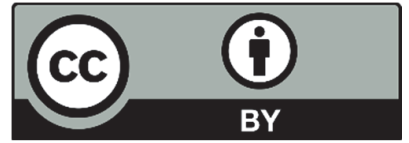

(C) 2019 by the authors; licensee Growing Science, Canada. This is an open access article distributed under the terms and conditions of the Creative Commons Attribution (CC-BY) license (http://creativecommons.org/licenses/by/4.0/). 